\title{
Micrometer per Day
}

National Cancer Institute

\section{Source}

National Cancer Institute. Micrometer per Day. NCI Thesaurus. Code C126081.

A unit of volumetric flow rate defined as the rate at which one micrometer of matter crosses a given surface during the period of time equal to one day. 